Research Paper

\title{
GPo1 alkB gene expression for improvement of the degradation of diesel oil by a bacterial consortium
}

\author{
Qun Luo, Ying He, Deng-Yong Hou, Jian-Guo Zhang, Xian-Rong Shen \\ The Naval Medical Research Institute, Shanghai, China.
}

Submitted: October 20, 2012; Approved: October 30, 2014

\begin{abstract}
To facilitate the biodegradation of diesel oil, an oil biodegradation bacterial consortium was constructed. The alkane hydroxylase (alkB) gene of Pseudomonas putida GPol was constructed in a pCom8 expression vector, and the pCom8-GPo1 alkB plasmid was transformed into Escherichia coli DH5 $\alpha$. The AlkB protein was expressed by diesel oil induction and detected through SDS-polyacrylamide gel electrophoresis. The culture of the recombinant (pCom8-GPo1 alkB/E. coli DH5 $\alpha$ ) with the oil biodegradation bacterial consortium increased the degradation ratio of diesel oil at $24 \mathrm{~h}$ from $31 \%$ to $50 \%$, and the facilitation rates were increased as the proportion of pCom8-GPo1 alkB/E. coli DH5 $\alpha$ to the consortium increased. The results suggested that the expression of the GPo1 gene in E. coli $\mathrm{DH} 5 \alpha$ could enhance the function of diesel oil degradation by the bacterial consortium.
\end{abstract}

Key words: alkane hydroxylase, expression, Escherichia coli DH5 $\alpha$, biodegradation, diesel oil.

\section{Introduction}

Marine petroleum pollution has become a great concern to all countries worldwide. Adding the average anthropogenic input and the natural input, the global annual marine oil discharge has been found to be 7 million tonnes (Luise and Thomas, 2005). Aside from the frequency and the amount of oil that regularly pollutes the environment, oil has many adverse properties that threaten the ecosystem and human health (Jeong and Cho, 2007). In recent decades, environmental biotechnology has offered many solutions for marine petroleum pollution and has become a promising technology for sustainable development (Young and Haggblom, 1991). Because microorganisms have diverse catabolic pathways for breaking down many persistent toxic compounds under gentle conditions with no emission and few by-products, biodegradation is believed to have great potential for pollutant treatment.

Due to developments in molecular biology and analytical chemistry, biodegradation pathways for hydrocarbon have been clearly elucidated. Alkanes are chemically quite inert and have to be activated to allow further metabolic steps to take place. The key step of hydrocarbon degradation is the addition of one and sometimes two oxygen atoms to the hydrocarbon molecule, which is then con- verted to an alkanol (in the case of aliphatic hydrocarbons) or a phenol (in the case of aromatic molecules) (Yong and Zhong, 2010). The alkane hydroxylase (AlkB), which catalyse the first reaction, is the key enzyme in the process of alkane degradation and has received increasing attention. From a biotechnological perspective, alkane hydroxylases are versatile biocatalysts that carry out a wide range of useful oxidation reactions (Grund et al., 1975). Different enzyme systems are known to perform the primary attack for the degradation of hydrocarbon. The alkane hydroxylase system of Pseudomonas putida GPol (commonly known as Pseudomonas oleovorans GPo1=TF41L=ATCC 29347) (Baptist et al., 1963), which can grow on alkanes ranging from pentane to dodecane and can be used to carry out a wide range of stereo- and regioselective oxidation reactions (Witholt et al., 1990), has been studied in detail with respect to both enzymology $(16,20)$ and genetics of the n-alkane metabolism (Kok et al., 1989a; Kok et al., 1989b). This alkane hydroxylase is the prototype of a very diverse collection of related non-heme iron integral membrane oxygenases (Shanklin and Cahoon, 1998; Smits et al., 1999). The detection of genes that are closely related to the alkane hydroxylase gene (alkB) of GPo1 in a large fraction of the microbial population in oil-contaminated en- 
vironments shows that this alkane hydroxylase plays an important role in the degradation of hydrocarbon (Sotsky et al., 1994).

Diesel oil is a complex mixture of different types of hydrocarbons $\left(\mathrm{C}_{6}\right.$ to $\left.\mathrm{C}_{22}\right)$ and branched alkanes, such as 2,6,10,14-tetramethyl pentadecane (pristine) and 2,4,6,10tetramethyl hexadecane (phytane). The limiting factor affecting the rate and range of hydrocarbon degradation in diesel oil by microorganisms appears to be the lack of ability of most microbial strains to utilize different components of diesel oil. Different strains can degrade different components, but a single strain can usually attack a limited number of hydrocarbons. Hence, a bacterial consortium is more nutritionally versatile than a single strain and exhibits considerable competence in utilizing a large number of hydrocarbon components from oil. Soli and Bens (Soli and Bens, 1973) successfully used a crude oil biodegradation bacterial consortium composed of different strains that can degrade either aliphatic, aromatic, or polynuclear aromatic hydrocarbons to degrade most components of crude oil.

To facilitate the biodegradation of diesel oil, an oil biodegradation bacterial consortium was constructed in this study. The GPo1 alkane hydroxylase (alkB) gene was synthesized in vitro, and a GPo1 alkB-expression vector, denoted $\mathrm{pCom} 8-\mathrm{GPo} 1$ alkB, was constructed and transformed into $E$. coli $\mathrm{DH} 5 \alpha$. The expression of GPo1 AlkB protein in the recombinant (pCom8-GPo1 alkB/ E. coli DH5 $\alpha$ ) induced by diesel oil under different conditions was detected by SDS-polyacrylamide gel electrophoresis (SDS-PAGE). The effects of pCom8-GPo1 alkB/DH5 $\alpha$ on the degradation of diesel oil by bacterial consortium were also confirmed.

\section{Materials and Methods}

\section{Bacterial strains, plasmid and media}

The strains and plasmid used in this study are listed in Table 1. pCom8 is a broad-host-range expression vector for the alkB gene based on pUCP25 and the P. putida GPo1 alkB promoter (Smits et al., 1999).

Basal salts medium (BSM; $25 \mathrm{~g}$ of $\mathrm{NaCl}, 0.7 \mathrm{~g}$ of $\mathrm{KCl}, 0.7 \mathrm{~g}$ of $\mathrm{MgSO}_{4} 7 \mathrm{H}_{2} \mathrm{O}, 1 \mathrm{~g}$ of $\mathrm{NH}_{4} \mathrm{NO}_{3}, 2 \mathrm{~g}$ of $\mathrm{KH}_{2} \mathrm{PO}_{4}$, and $3 \mathrm{~g}$ of $\mathrm{Na}_{2} \mathrm{HPO}_{4} 2 \mathrm{H}_{2} \mathrm{O}$ ) was sterilized for $20 \mathrm{~min}$ at 121
${ }^{\circ} \mathrm{C}$ and supplemented with $2 \%$ microelements (sterilized by filtration through a $0.22-\mu \mathrm{m}$ membrane) at $\mathrm{pH} 7.5$. The medium was supplemented with diesel oil as the sole carbon source. The microelement solution contained $4 \mathrm{~g}$ of $\mathrm{MgSO}_{4} 7 \mathrm{H}_{2} \mathrm{O}, 1 \mathrm{~g}$ of $\mathrm{CuSO}_{4} 5 \mathrm{H}_{2} \mathrm{O}, 1 \mathrm{~g}$ of $\mathrm{MnSO}_{4} \mathrm{H}_{2} \mathrm{O}, 1 \mathrm{~g}$ of $\mathrm{FeSO}_{4} 7 \mathrm{H}_{2} \mathrm{O}$, and $1 \mathrm{~g}$ of $\mathrm{CaCl}_{2}$ per litre.

Luria-Bertani (LB) medium, SOB medium and SOC medium were used throughout this study. Gentamicin was used at a concentration of $10 \mu \mathrm{g} \mathrm{mL}^{-1}$.

\section{Synthesis of the GPo1 alkB gene and construction of the alkB-expressing vector pCom8-GPo1 alkB}

The GPo1 alkB gene, including the SalI and NdeI restriction enzyme sites, was synthesized in vitro by Shanghai Major Bio Technology Co. (Shanghai, China).

After digestion with SalI and NdeI, the GPol alkB gene was cloned in the pCom8 vector and transformed into competent $E$. coli $\mathrm{DH} 5 \alpha$. E. coli strains harbouring the recombinant plasmids were selected by LB medium with 10 $\mu \mathrm{g} \mathrm{mL}^{-1}$ gentamicin. The plasmid DNA was isolated using the High Pure Plasmid Isolation Kit (Takara Bio, China). The recombinant plasmids containing the desired genes from the transformants were identified by PCR, SalI and NdeI enzymolysis digestion and sequencing. The set of specific primers for the target gene was 5', TTGCTTGATGCGATGTTT 3' (forward) and 5' AGTCCGTTCACGATACCC 3' (reverse). The following PCR programme was used: initial denaturation at $94{ }^{\circ} \mathrm{C}$ for 10 min followed by 30 cycles of denaturation at $94{ }^{\circ} \mathrm{C}$ for $0.5 \mathrm{~min}$, annealing at $50^{\circ} \mathrm{C}$ for $0.5 \mathrm{~min}$, and elongation at $72{ }^{\circ} \mathrm{C}$ for $1 \mathrm{~min}$, a final elongation at $72{ }^{\circ} \mathrm{C}$ for $10 \mathrm{~min}$ and termination at $4{ }^{\circ} \mathrm{C}$. The restriction enzymes, T4 DNA ligase, DNA polymerase, T4 DNA polymerase, and PCR-related reagents were obtained from Shanghai Major Bio Technology Co. (Shanghai, China). The recombinant plasmids from these clones were named pCom8-GPo1 alkB, and the E. coli $\mathrm{DH} 5 \alpha$ strains harbouring recombinant plasmids were named pCom8-GPo1 alkB/DH5 $\alpha$.

\section{Expression of the GPo1 gene in E. coli $\mathrm{DH} 5 \alpha$}

Diesel oil (v/v: $0.5 \%, 1 \%$, and $2 \%$ ) was added as an inducer when pCom8-GPo1 alkB/DH5 $\alpha$ was in the logarithmic phase $(\mathrm{OD} 600,0.4)$ in LB medium with $10 \mu \mathrm{g} \mathrm{mL}^{-1}$

Table 1 - Strains and plasmid used in this study.

\begin{tabular}{lll}
\hline Strain & Relevant genotype, phenotype or characteristic(s) & Source or reference \\
\hline Y9 & Acinetobacter sp. & Laboratory collection \\
W3 & Acinetobacter sp. & Laboratory collection \\
F9 & Acinetobacter sp. & Laboratory collection \\
X1 & Gordonia sp. Biosurfactant-producing strain & Laboratory collection \\
E. coli DH5 2 & recA1 endA1 hsdR17 D lacU169 & Laboratory collection \\
pCom8 & alkB genes expression vector, PalkB; $\mathrm{Gm}^{\mathrm{r}}$ (gentamicin); oriT; alkS; broad host range & Smits et al., 2001 \\
\hline
\end{tabular}


gentamicin. After $4 \mathrm{~h}$, the fermentation was stopped, and the cells were harvested by centrifugation. At a diesel oil concentration of $1 \%(\mathrm{v} / \mathrm{v})$, the cells were harvested at different times $(2,4$ and $6 \mathrm{~h})$. The cell paste was pelleted $(12,000 \mathrm{~g}, 10 \mathrm{~min})$ and stored at $-20^{\circ} \mathrm{C}$ until use. The cell paste was resuspended in sterilized $\mathrm{ddH}_{2} 0$ and boiled for 5 min to disrupt the cells. The protein concentration of the supernatant containing the AlkB protein was determined using the Bradford reagent.

SDS-polyacrylamide gel electrophoresis (SDSPAGE) was performed using 10\% resolving gels (operation voltage: $120 \mathrm{~V}$ ) and $5 \%$ stacking gels (operation voltage: $80 \mathrm{~V}$ ). Approximately $20 \mu \mathrm{g}$ of protein was loaded per lane. The gels were stained with Coomassie Brilliant Blue R-250.

\section{Biodegradation assay}

Assays to test the degradation of diesel oil were performed in liquid culture using washed cell suspensions. The bacteria were inoculated into HLB medium from agar plates and incubated aerobically at $30{ }^{\circ} \mathrm{C}$ on an orbital shaker at $200 \mathrm{rpm}$ for approximately $16 \mathrm{~h}$. When the optical density $\left(\mathrm{OD}_{600}\right)$ of the bacterial suspension was 1.0 , the bacterial suspension was centrifuged for $10 \mathrm{~min}$ at $3000 \mathrm{rpm}$. After the supernatant was discarded and the wet bacteria was washed with sterilized BSM liquid medium, the cell suspensions were inoculated into $250-\mathrm{mL}$ conical flasks containing sterilized liquid culture (per flask: $100 \mathrm{~mL}$ of BSM with a specified amount of diesel oil) and incubated in the dark on an orbital shaker at $180 \mathrm{rpm}$ and $30^{\circ} \mathrm{C}$ until the time when they were removed for sampling. The remaining oil was extracted three times from the culture fluid with $20 \mathrm{~mL}$ of petroleum ether $\left(60-90^{\circ} \mathrm{C}\right)$, and the organic phase was then collected after extraction and analysed using a UV spectrophotometer. Using petroleum ether as the blank reference, the UV absorbance was measured at $255 \mathrm{~nm}$. All biodegradation experiments were performed three times in triplicate, and sterilized cultures without inoculation were used as a negative control.

\section{Construction of the bacteria consortium}

Four strains (Y9, W3, F9 and X1) screened from oil-contaminated seawater were chosen for constructing an oil biodegradation bacterial consortium. The construction of the bacterial consortium was optimized via an orthogonal experiment. The trials were performed in BSM inoculated with a $4.0 \%(\mathrm{v} / \mathrm{v})$ target strain under the principle of equal with $1 \%(\mathrm{v} / \mathrm{v})$ diesel oil. The cells were incubated at
$30{ }^{\circ} \mathrm{C}$ with shaking at $180 \mathrm{rpm}$ for three days. The proportion of each inoculated strain was equal in each bacterial consortium. The degradation ratios were detected at 24,48 , and $72 \mathrm{~h}$, as described in the prior section.

\section{Effects of pCom8-GPo1 alkB/DH5 $\alpha$ on diesel oil degradation}

To investigate the effects of pCom8-GPo1 $a l k B / \mathrm{DH} 5 \alpha$ on the degradation of diesel oil by the bacterial consortium, biodegradable assays were performed using three groups: the blank control containing $2 \mathrm{~mL}$ of the bacterial consortium $(0.5 \mathrm{~mL}$ of each of the strains Y9, W3, F9 and $\mathrm{X} 1$ ), the negative control containing $2 \mathrm{~mL}$ of the bacterial consortium and $2 \mathrm{~mL}$ of strain DH5 $\alpha$, and the experimental group containing $2 \mathrm{~mL}$ of the bacterial consortium and $2 \mathrm{~mL}$ of strain pCom8-GPo1 alkB/DH5 $\alpha$. The degradation ratio was detected at 24,48 , and $72 \mathrm{~h}$. The bacterial counts were determined using the MPN method. Strain pCom8-GPo1 alkB/DH5 $\alpha$ was selected with appropriate antibiotics (gentamicin, $10 \mu \mathrm{g} \mathrm{mL}^{-1}$ ).

Five biodegradation assays (Table 2) were prepared to evaluate the effect of different proportions of the bacterial consortium and pCom8-GPo1 alkB/DH5 $\alpha$ through biodegradable assays. The degradation ratio was detected at $24 \mathrm{~h}$.

\section{Gas chromatography-mass spectrometry analysis}

The degradation effect of diesel oil was examined by GC-MS (Thermo Focus DSQ GC-MS, USA). The diesel oil remaining in the liquid culture was extracted three times with $20 \mathrm{~mL}$ of dichloromethane. The organic phase was dehydrated with anhydrous sodium sulfate, and $1 \mu \mathrm{L}$ of the organic phase was analysed by GC-MS. The gas chromatograph was equipped with a split-splitless injector (split ratios of 50:1) and an HP-5 MS column (30 $\mathrm{m} \mathrm{x} 0.25 \mathrm{~mm} \times$ $0.25 \mu \mathrm{m}$; Agilent Technologies). The oven temperature was initially maintained at $60^{\circ} \mathrm{C}$ for $2 \mathrm{~min}$, programmed to increase to $300{ }^{\circ} \mathrm{C}$ at a rate of $20^{\circ} \mathrm{C} \mathrm{min}^{-1}$ and then maintained at this temperature for $5 \mathrm{~min}$. The temperatures of the injector, transfer line and ionization source were all $250^{\circ} \mathrm{C}$. The electron impact ionization was tuned to $70 \mathrm{eV}$, and helium was used as the carrier gas with an average linear velocity of $1.0 \mathrm{mLmin}^{-1}$. The mass spectra were recorded within 41-400 amu to collect the total ion current (TIC) chromatograms.

Table 2 - Bacterium used for inoculation in the experimental sets.

\begin{tabular}{lcccc}
\hline Proportion & $1: 3$ & $1: 2$ & $1: 1$ & Blank control \\
\hline Bacterial consortium & $2 \mathrm{~mL}$ & $2 \mathrm{~mL}$ & $2 \mathrm{~mL}$ & $2 \mathrm{~mL}$ \\
pCom8-GPo1 alkB/DH5 & $6 \mathrm{~mL}$ & $4 \mathrm{~mL}$ & $2 \mathrm{~mL}$ & $1 \mathrm{~mL}$ \\
\hline
\end{tabular}




\section{Results}

\section{Construction of the alkB-expressing vector pCom8-GPo1 alkB}

In this study, the GPo1 alkB gene (approximately 1203 bps in length) was cloned into the multiple cloning sites of the pCom8 vector. The physical map of the recombinant plasmid is shown in Figure 1. The recombinant vector pCom8-GPo1 alkB was transformed into competent $E$. coli $\mathrm{DH} 5 \alpha$, and positive transformants were selected by antibiotics (gentamicin, $10 \mu \mathrm{g} \mathrm{mL} \mathrm{m}^{-1}$ ). The recombinant plasmid pCom8- GPo1 alkB was isolated using a High Pure Plasmid Isolation Kit (Takara Bio, China) and prepared for electroporation, and identified by PCR and digestion with SalI and NdeI. The agarose gel electrophoresis results of pCom8-GPo1 alkB, which was digested with SalI and NdeI, are shown in Figure 2. The agarose gel electrophoresis results suggested that the size of the inserted gene fragment was approximately $1200 \mathrm{bps}$, which is equal to that of the predicated fragment. As shown in Figure 3, pCom8GPo1 alkB/DH5 $\alpha$ and the isolated recombinant plasmid pCom8-GPo1 alkB were used as templates for PCR. The results demonstrated that the transformation was succeeded. The sequencing results also suggested that the recombinant plasmid pCom8-GPo1 alkB was correctly constructed.

\section{Expression of the GPo1 alkane hydroxylase gene}

To investigate the expression levels and induction conditions, the protein expression in pCom8-GPo1

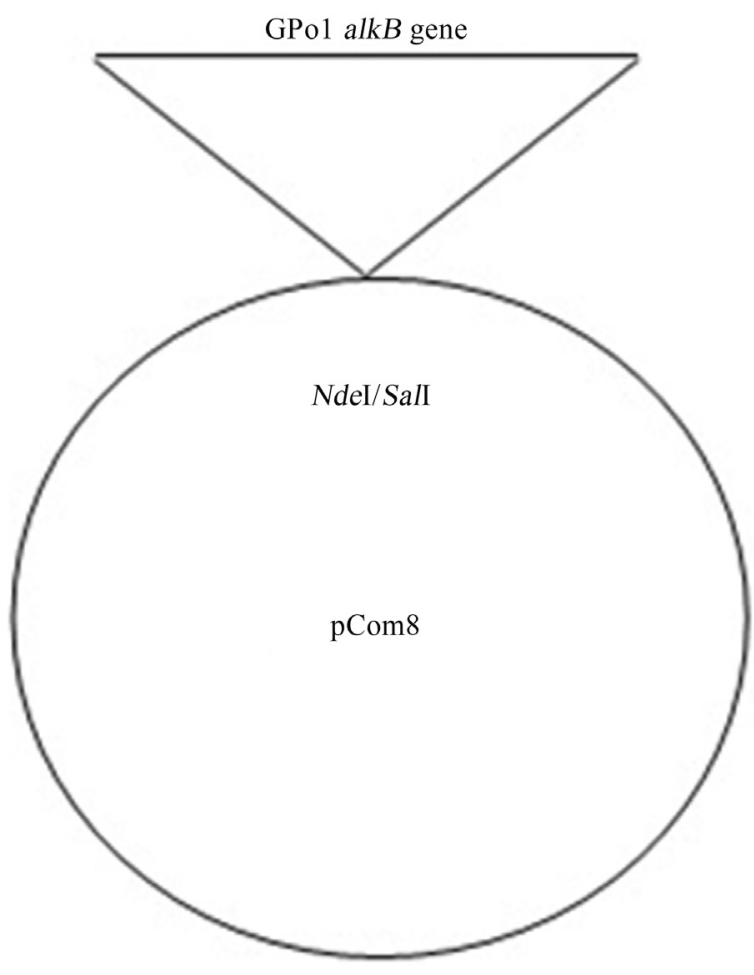

Figure 1 - Physical map of the recombinant plasmid.
alkB/DH5 $\alpha$ and E. coli DH5 $\alpha$ was identified by SDSPAGE. The GPo1 AlkB protein was $51 \mathrm{kD}$. As shown in Figure 4, bands of $51 \mathrm{kD}$ were observed in the lanes of pCom8-GPo1 alkB/DH5 $\alpha$. These bands correspond to the GPo1 AlkB protein. The grey level of the different bands revealed the differences in expression level between induction and noninduction conditions, but there was no significant difference when pCom8-GPo1 alkB/DH5 $\alpha$ was induced with different concentrations of diesel oil. The ex-

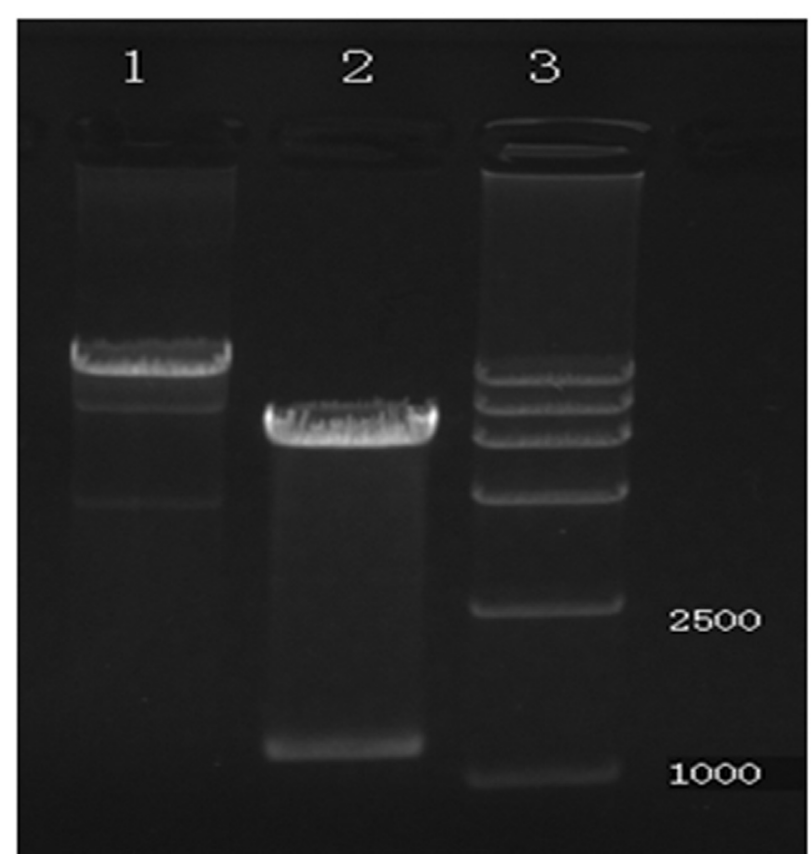

Figure 2 - Agarose gel electrophoresis of the results of enzyme digestion: Lane 1, pCom8-GPo1 alkB; 2, pCom8-GPo1 alkB digestion with SalI and NdeI; and 3, DL15000.

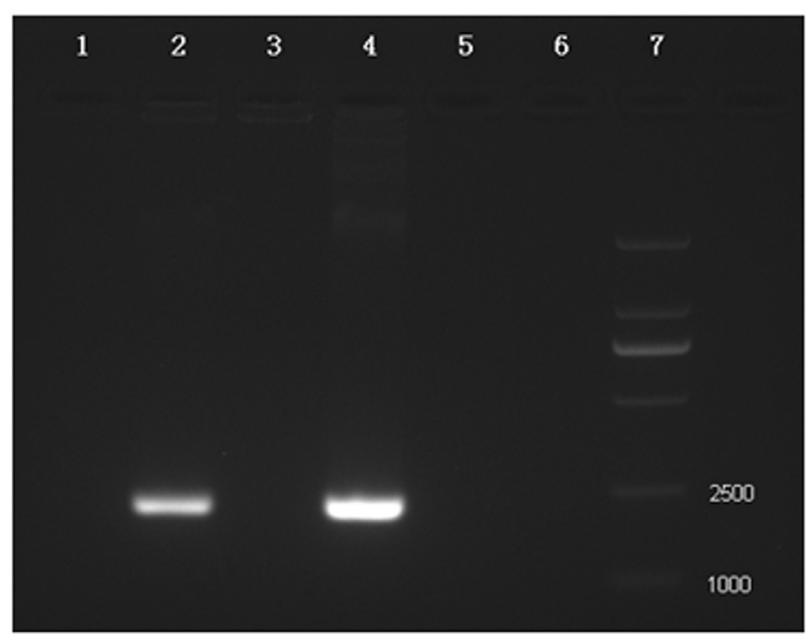

Figure 3 - Agarose gel electrophoresis of PCR products: Lane 1, bacterial consortium; 2, pCom8-GPo1 alkB/DH5 $\alpha$; 3, DH5 $\alpha$; 4, pCom8- GPo1 alkB; 5, pCom8; 6, blank control; and 7, DL15000. 

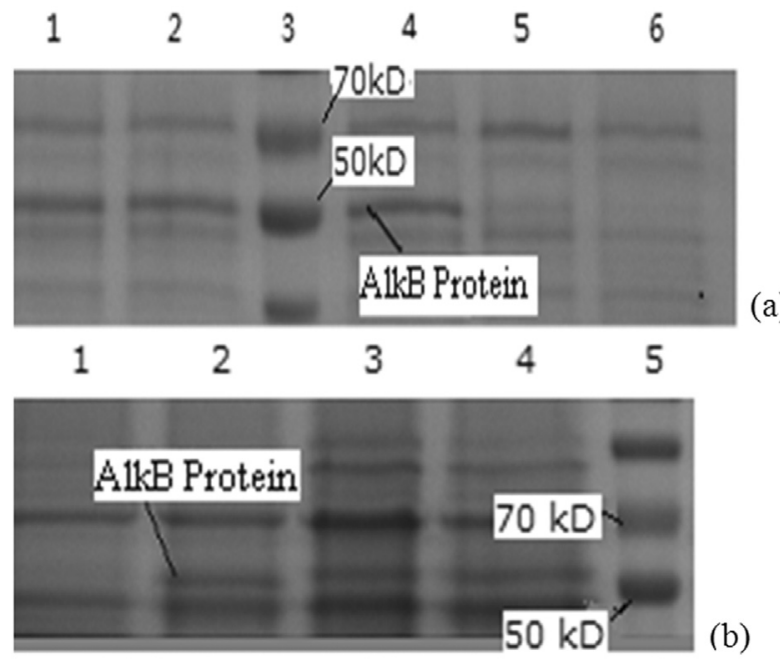

Figure 4 - Protein gels of the GPo1 alkB gene. a, induction with different concentrations of diesel oil: $1,2 \% ; 2,1 \% ; 3$, protein marker; $4,0.5 \% ; 5$, noninduction; $6, \mathrm{DH} 5 \alpha$ noninduction. b: induction for different times: 1 , DH5 $\alpha$ noninduction; 2, $2 \mathrm{~h} ; 3,4 \mathrm{~h} ; 4,6 \mathrm{~h} ; 5$, protein marker.

pression levels increased slightly with an increase in the induction time.

\section{Construction of diesel oil biodegradation bacterial consortium}

To facilitate the biodegradation of diesel oil, four strains (Y9, W3, F9 and X1) screened from oil-contaminated sea were chosen to construct an oil biodegradation bacterial consortium. The strains Y9, W3 and F9 were Acinetobacter sp., which can use diesel oil as the sole car- bon source and degrade most components of diesel oil, and strain X1 was a biosurfactant-producing strain. The biodegradation ratio of the bacterial consortium, which was composed of four strains (Y9, W3, F9 and X1), was higher than that of the other consortiums (data not shown), and it was adopted for further investigations of the target.

As shown in Figure 5, the biodegradation ratios of the optimal bacterial consortium were obviously higher than those of the strains Y9, W3, F9 and X1 alone from 24 to $72 \mathrm{~h}$. At $24 \mathrm{~h}$, the biodegradation ratio of the consortium reached $31 \%$, but the strains $\mathrm{Y} 9, \mathrm{~W} 3$ and $\mathrm{F} 9$ required 48 or 72 hours, and strain $\mathrm{X} 1$ required much more than $72 \mathrm{~h}$ to achieve this ratio. The biodegradation ratio of the consortium was still higher $(50 \%)$ than those of the strain $\mathrm{Y} 9, \mathrm{~W} 3$, $\mathrm{F} 9$ and $\mathrm{X} 1$ alone (35\%, $37 \%, 42 \%$ and $22 \%$, respectively) at $72 \mathrm{~h}$.

\section{Effect of pCom8-GPo1 alkB/DH5 $\alpha$ on the degradation of diesel oil by the bacterial consortium}

The biodegradation ratios of the blank control (consortium), negative control (consortium + DH5 $\alpha$ ) and experimental group (consortium + pCom8-GPo1 alkB/DH5 $\alpha$ ) at 24, 48, and $72 \mathrm{~h}$, are shown in Figure 6. At $24 \mathrm{~h}$, the biodegradation ratio of the experimental group $(50 \%)$ was obviously higher than those of the negative control (31\%) and blank control (27\%). These results suggested that pCom8-GPo1 alkB/DH5 $\alpha$ promotes the earlier degradation of diesel oil by the consortium and markedly improved the degradation ratio. The biodegradation ratio of the negative control (31\%) was slightly higher than that of

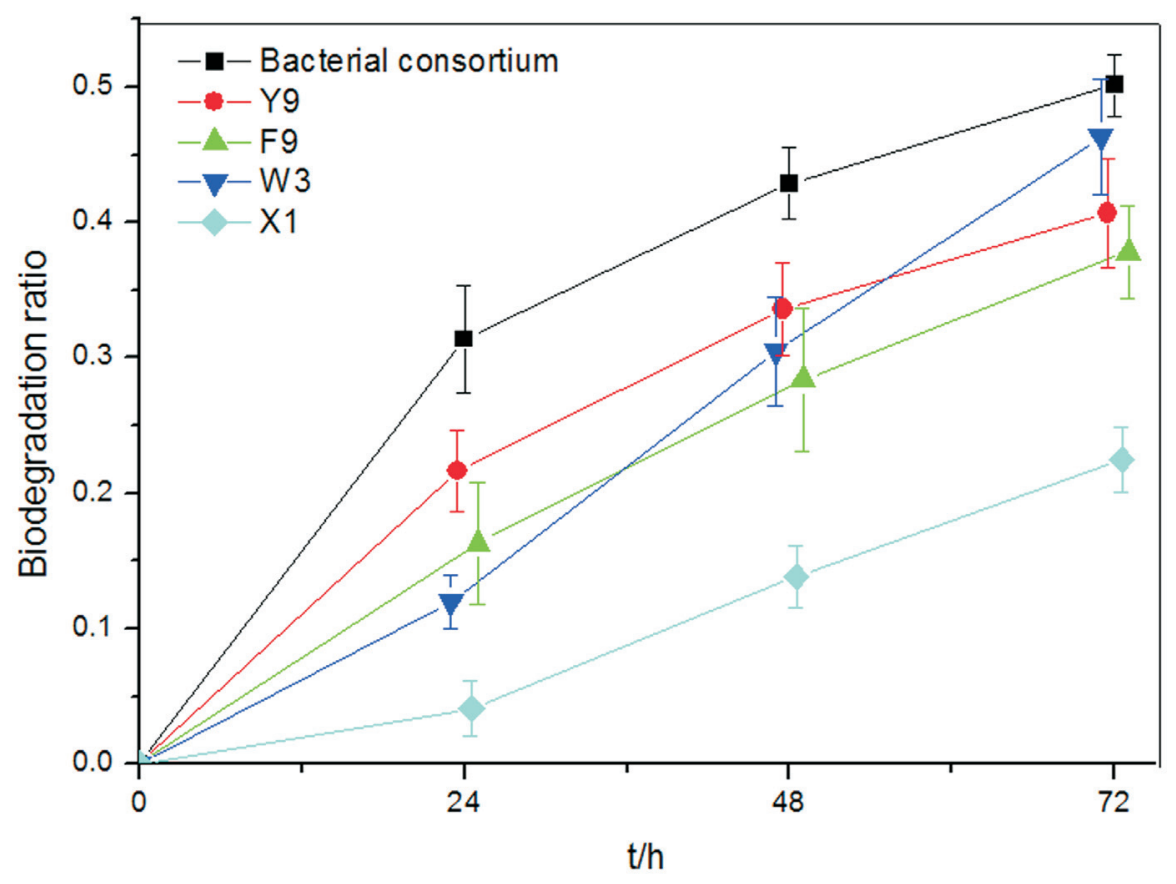

Figure 5 - Biodegradation ratio of diesel oil by the consortium and the strains Y9, W3, F9 and X1 alone. The error bars indicate the SDs. 


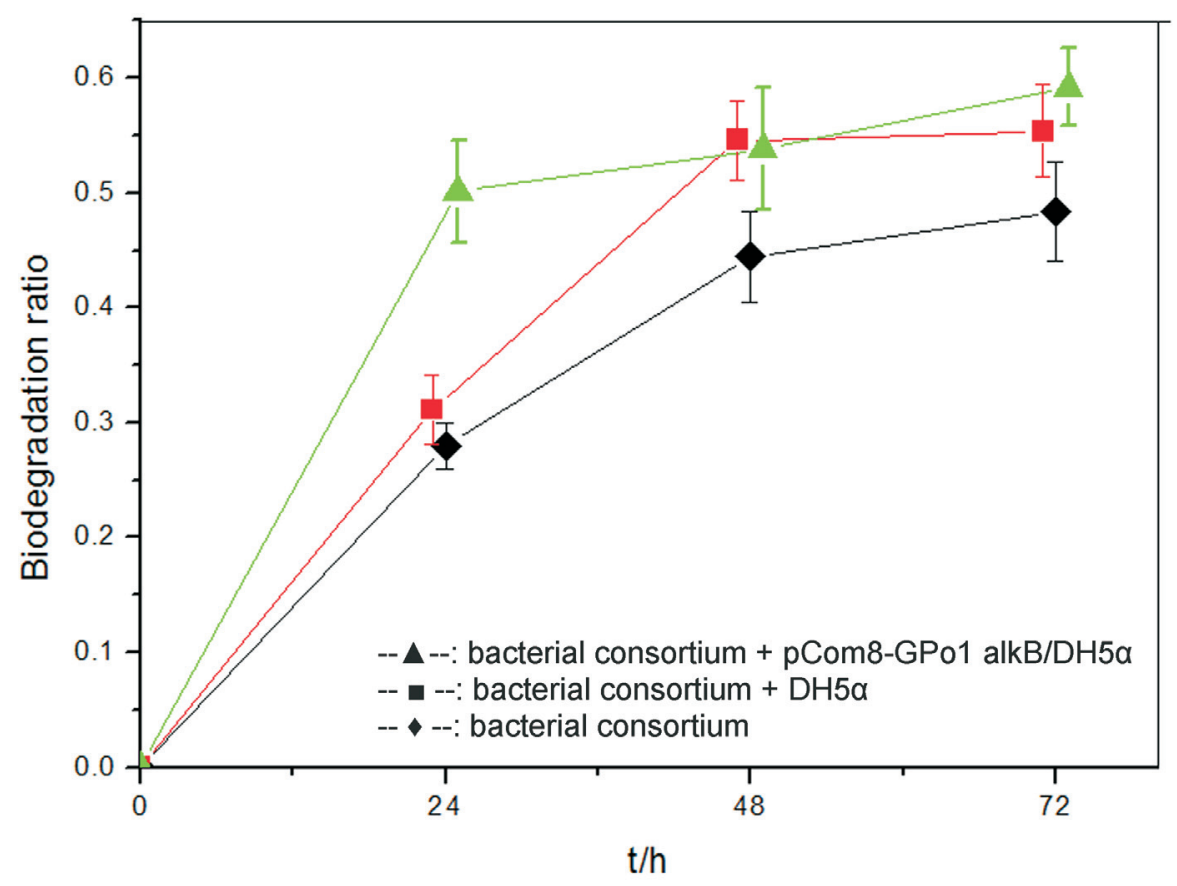

Figure 6 - Effect of pCom8-GPo1 alkB/DH5 $\alpha$ on the degradation of diesel oil by the bacterial consortium. The error bars are the SDs.

the blank control (27\%) probably because E. coli $\mathrm{DH} 5 \alpha$ can also utilize the by-products of the consortium. After $24 \mathrm{~h}$ of incubation, the remaining diesel oil in the experimental cultures was extracted three times with $20 \mathrm{~mL}$ of dichloromethane. The organic phase was then dehydrated with anhydrous sodium sulfate, and $1 \mu \mathrm{L}$ of the organic phase was analysed by GC-MS. The chromatograms of the remaining diesel oil are shown in Figure 7. Diesel oil was chosen as the model oil substrate due to its extensive applications in industrial fuels and the power supply for transportation. The components of diesel oil identified on the chromatogram were mixed hydrocarbons (C11-C21), and all of the components of the diesel oil could be degraded. The abundance of the remaining diesel oil in the experi- mental group was lower than those of the blank control and negative control.

The total counts of bacteria and the counts of pCom8-GPo1 alkB/DH5 $\alpha$ in the experimental group during the diesel oil degradation process are shown in Figure 8. The counts of pCom8-GPo1 alkB/DH5 $\alpha$ increased from $3 \times 10^{8}$ to $4 \times 10^{8}$ cells $\mathrm{mL}^{-1}$ at $24 \mathrm{~h}$ and remained relative constant at 48 and $72 \mathrm{~h}$. The total counts of bacteria increased obviously from $1 \times 10^{10}$ to $110 \times 10^{10}$ cells $\mathrm{mL}^{-1}$ at $24 \mathrm{~h}$ and then increased slowly from $130 \times 10^{10}$ to $150 \times 10^{10}$ cells $\mathrm{mL}^{-1}$ over the next $48 \mathrm{~h}$. These tendencies were consistent with the biodegradation ratio of the experimental group, which increased very rapidly over the first $24 \mathrm{~h}$ and slowly over the next $48 \mathrm{~h}$. After $24 \mathrm{~h}$, the bacteria were in the stable

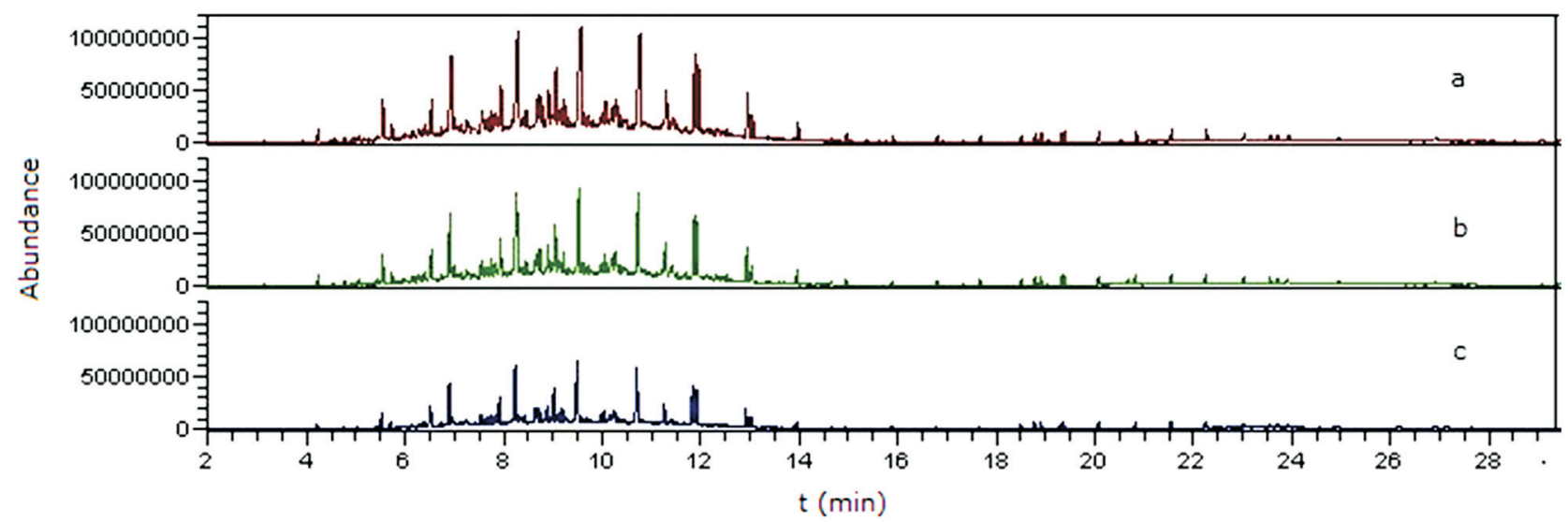

Figure 7 - Chromatogram of the remaining diesel oil in the experimental culture: a, blank control; b, negative control; and c, experimental group. 


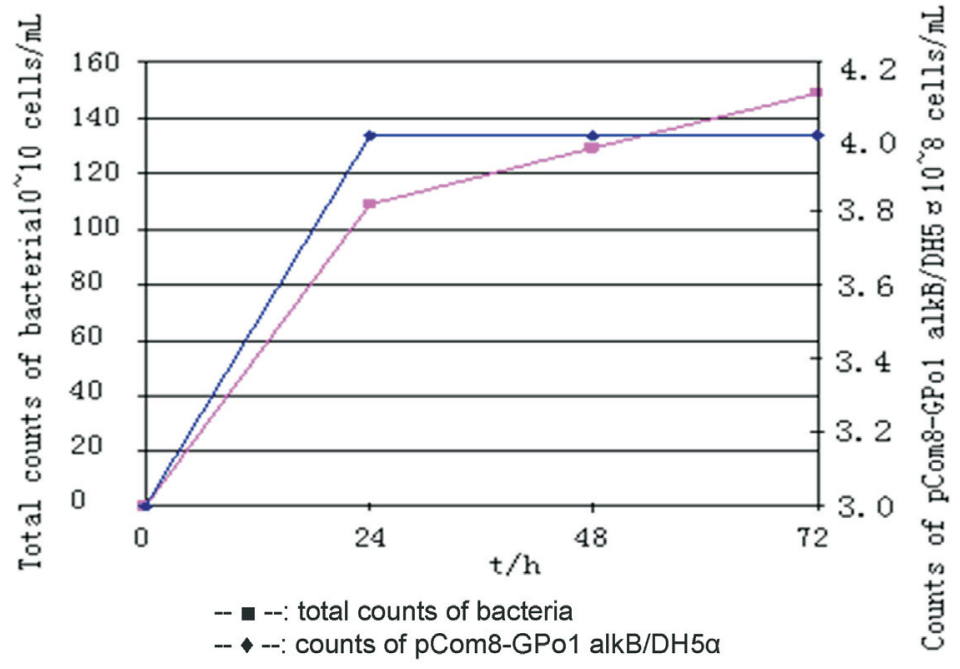

Figure 8 - Total counts of bacteria and counts of pCom8-GPo1 alkB/DH5 $\alpha$ in the experimental group during diesel oil degradation.

phase, during which the counts remained relative constant, and the biodegradation ratio grew slowly. This result was in agreement with those of another study conducted in our laboratory (Luo et al., 2013).

The effects of different proportions of the consortium and pCom8-GPo1 alkB/DH5 $\alpha$ on the degradation ratio of diesel oil were also investigated. As shown in Figure 9, the degradation ratios obtained with different proportions were $38.2 \%, 38.3 \%, 42.1 \%$ and $49.1 \%$ at $24 \mathrm{~h}$, all of which higher than that of the blank control (31.4\%). The biodegradation ratio decreased with an increase in the proportion of the consortium and pCom8-GPo1 alkB/DH5 $\alpha$, indicating that the facilitation rates increased as the proportion of pCom8-GPo1 alkB/DH5 $\alpha$ increased. This was probably because more pCom8-GPo1 alkB/DH5 $\alpha$ can express more AlkB protein, which oxidizes $n$-alkanes to 1 -alkanols, and improve the degradation ratio of diesel oil.

\section{Discussion}

The use of bioremediation as a supplemental cleanup strategy in the Exxon Valdez oil spill in Prince William Sound, Alaska, has proven to be a good example of the problems and successes associated with the practical application of this technology. Biodegradation as a natural process may proceed slowly and is a long-term (weeks to months) process from a response point of view. Biodegradation has been popularized as the 'ultimate' solution to oil spills but not as the first-response tool. The slow rate of the biodegradation process is a bottleneck that limits its application for site remediation. Various methodologies of bioremediation have been applied to increase the rate or extent of the biodegradation process, including optimizing various physical, chemical, and biological conditions in the contaminated environment, constructing degrading bacterial consortiums, and genetic engineering bacteria.

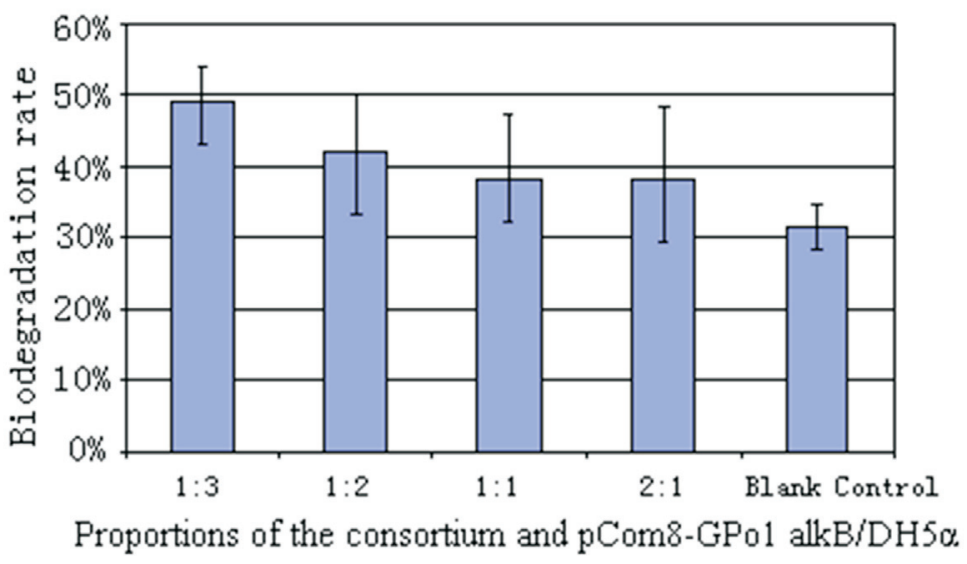

Figure 9 - Biodegradation ratio of diesel oil by different proportions of the bacterial consortium and pCom8-GPo1 alkB/DH5 $\alpha$ at $24 \mathrm{~h}$. The error bars are the SDs. 
Various genetic approaches have been developed and used to optimize the enzymes, metabolic pathways and organisms relevant for biodegradation. New information on the metabolic routes and bottlenecks of degradation is still being accumulated, enlarging the available toolbox. The first and key step in alkane metabolism is the terminal hydroxylation of alkanes to 1-alkanols, a reaction catalysed by a family of integral-membrane diiron enzymes related to Pseudomonas putida GPo1 AlkB by a diverse group of methane, propane, and butane monooxygenases and by some membrane-bound cytochrome P450s (Funhoff et al., 2006). The Pseudomonas putida GPol alkane hydroxylase can oxidize $n$-alkanes to 1 -alkanols. pCom8, which contains oriT, alkS (Canosa et al., 2000), and PalkB (Pseudomonas putida (oleovorans) GPo1 alkB promoter) (Smits et al., 1999), was a useful expression vector for heterologous expression and exhibited a medium to high copy number in E. coli. The expression of the PalkB promoter was modulated by catabolite repression depending on the carbon source being used (Yuste et al., 1998; Staijen et al., 1999). The positive regulator of PalkB, AlkS (Canosa et al., 2000), could be activated by C7-C12 $n$-alkanes, alkenes, and gratuitous inducers (Grund et al., 1975; Wubbolts, 1994). In this study, the expression of the GPo1 AlkB protein in pCom8-GPo1 alkB/DH5 $\alpha$ indicated that diesel oil was

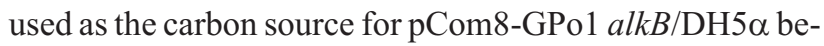
cause it causes the catabolite repression of PalkB. The culture of pCom8-GPo1 alkB/DH5 $\alpha$ with the oil biodegradation bacterial consortium, which was constructed successfully to improve the biodegradation of diesel oil, increased the degradation ratio of diesel oil from $31 \%$ to $50 \%$ at $24 \mathrm{~h}$, and the facilitation rates were increased as the proportion of pCom8-GPo1 alkB/DH5 $\alpha$ increased. These results suggested that pCom8-GPo1 alkB/DH5 $\alpha$ and the consortium can use each other's intermediate metabolites, and the expression of GPo1 AlkB, which can oxidize $n$-alkanes to 1-alkanols, would accelerate the biodegradation of diesel oil. This finding also indicated that the first step in alkane degradation may be the rate-limiting step and that GPo1 alkane hydroxylase plays an important role in the first step of alkane metabolism.

In summary, in this study, an oil biodegradation bacterial consortium was constructed for the biodegradation of diesel oil using three Acinetobacter sp. strains and one biosurfactant-producing strain. The findings demonstrated that the expression of GPo1 AlkB in pCom8-GPo1 alkB/DH5 $\alpha$ improved the rate of diesel oil degradation by the consortium. These results not only provide an effective method for improving the biodegradation rate of diesel oil but also suggest a feasible way to construct multi-plasmid genetically engineered microorganisms for rapid degradation hydrocarbon, which is now in progress in our laboratory. With the development of an effective biodegradation technology, the study of the bioremediation of marine oil pollution would undergo further progress.

\section{Acknowledgments}

This work was supported by a grant from the Shanghai Natural Science Foundation of China (No. 08ZR1401300).

\section{References}

Baptist JN, Gholson RK, Coon MJ (1963) Hydrocarbon oxidation by a bacterial enzyme system: I Products of octane oxidation. Biochim Biophys Acta 69:40-47.

Canosa I, Sanchez-Romero JM, Yuste L et al. (2000) A positive feedback mechanism controls expression of AlkS, the transcriptional regulator of the Pseudomonas oleovorans alkane degradation pathway. Mol Microbiol 35:791-799.

Funhoff EG, Bauer U, Garcia-Rubio I et al. (2006) CYP153A6, a soluble P450 oxygenase catalyzing terminal-alkane hydroxylation. J bacterial 188:5220-5227.

Grund A, Shapiro J, Fennewald M et al. (1975) Regulation of alkane oxidation in Pseudomonas putida. J Bacteriol 123:546-556.

Hou CT, Jackson MA, Bagby MO et al. (1994) Microbial oxidation of cumene by octane-grown cells. Appl Microbiol Biotechnol 41:178-182.

Jeong WG, Cho SM (2007) Long-term effect of polycyclic aromatic hydrocarbon on physiological metabolisms of the Pacific oyster Crassostrea gigas. Aquacult 265:343-350.

Kok M, Oldenhuis R, van der Linden MPG et al. (1989a) The Pseudomonas oleovorans alkBAC operon encodes two structurally related rubredoxins and an aldehyde dehydrogenase. J Biol Chem 264:5442-5451.

Kok M, Oldenhuis R, van der Linden MPG et al. (1989b) The Pseudomonas oleovorans alkane hydroxylase gene sequence and expression. J Biol Chem 264:5435-5441.

Luise BC, Thomas H (2005) Geo-biological aspects of coastal oil pollution. Palaeogeogr Palaeocl 219:171-189.

Luo Q, Zhang JG, Shen XR et al. (2013) Isolation and characterization of marine diesel oil-degrading Acinetobacter sp. strain Y2. Ann Microbiol 63:633-640.

Shanklin J, Cahoon EB (1998) Desaturation and related modifications of fatty acids. Annu Rev Plant Physiol Plant Mol Biol 49:611-641.

Smits THM, Röthlisberger M, Witholt B et al. (1999) Molecular screening for alkane hydroxylase genes in Gram-negative and Gram-positive strains. Environ Microbiol 1:307-318.

Sotsky JB, Greer CW, Atlas RM (1994) Frequency of genes in aromatic and aliphatic hydrocarbon biodegradation pathways within bacterial populations from Alaskan sediments. Can J Microbiol 40:981-985.

Soli G, Bens EM (1973) Selective substrate utilization by marine hydrocarbon oxidize bacteria. Biotech Bioeng 15:285-297.

Staijen IE, Marcionelli R, Witholt B (1999) The PalkBFGHJKL promoter is under carbon catabolite repression control in Pseudomonas oleovorans but not in Escherichia coli alk1 recombinants. J Bacteriol 181:1610-1616.

Ueda T, Lode ET, Coon MJ (1972a) Enzymatic v-oxidationVII Reduced diphosphopyridine nucleotide-rubredoxin reduc- 
tase: properties and function as an electron carrier in vhydroxylation. J Biol Chem 247:5010-5016.

Ueda T, Lode ET, Coon MJ (1972b) Enzymatic v-oxidation VI Isolation of homogeneous reduced diphosphopyridine nucleotide-rubredoxin reductase. J Biol Chem 247:2109-2116.

Witholt B, de Smet MJ, Kingma J et al. (1990) Bioconversions of aliphatic compounds by Pseudomonas oleovorans in multiphase bioreactors: background and economic potential. Trends Biotechnol 8:46-52.

Wubbolts MG (1994) Xylene and Alkane Mono-oxygenases from Pseudomonas putida. PhD Thesis, University of Groningen, Groningen, The Netherlands.
Young LY, Haggblom MM (1991) Biodegradation of toxic and environmental pollutants. Curr Opin Biotechnol 2:429-435.

Yong YC, Zhong JJ (2010) Recent advances in biodegradation in China: New microorganisms and pathways, biodegradation engineering, and bioenergy from pollutant biodegradation. Process Biochem 45:1937-1943.

Yuste L, Canosa I, Rojo F (1998) Carbon-source dependent expression of the PalkB promoter from the Pseudomonas oleovorans alkane degradation pathway. J Bacteriol 180:5218-5226.

Associate Editor: Raquel Silva Peixoto

All the content of the journal, except where otherwise noted, is licensed under a Creative Commons License CC BY-NC. 